\title{
Evolução diária e variação sazonal da turbulência atmosférica em espaços livres de cidades do Oeste Paulista
}

\section{Antonio Jaschke Machado}

Bacharel em Meteorologia, Doutor em Geografia Física. Docente dos Cursos de Arquitetura e Urbanismo, e Geografia da FCT-UNESP, pesquisador dos Laboratórios de Climatologia, Clima e Conforto e Estação

Meteorológica. Presidente Prudente [SP] Brasil. <jaschke.machado@gmail.com>

\begin{abstract}
Resumo
Este artigo procura identificar um padrão da turbulência do ar que reflita o efeito de edifícios nas características da turbulência medida em espaços livres de cidades do Oeste Paulista. A turbulência atmosférica foi estimada utilizando-se observações de alta-frequência das três componentes ortogonais do vento $(\mathrm{u}, \mathrm{v}, \mathrm{w})$. Um anemômetro sônico CSAT3 da Campbell Scientific Inc. (CSI) foi instalado na cobertura de um edifício, e as componentes turbulentas $\left(\mathrm{u}^{\prime}, \mathrm{v}^{\prime}, \mathrm{w}^{\prime}\right)$ foram sistematicamente medidas e registradas em intervalos de $0.1 \mathrm{~s}$ e 5 min, respectivamente, durante 1 ano entre março de 2015 e fevereiro de 2016 com um sistema automático de aquisição de dados CR3000 (CSI). A análise dos dados considerou a variabilidade diurna e noturna da turbulência, e os resultados experimentais revelaram a existência de um padrão diário de circulação vertical. A componente w variou entre 15 e $45 \mathrm{~cm} . \mathrm{s}-1$ em média, e as flutuações turbulentas observadas indicaram que uma componente ascendente com uma velocidade de até 1 m.s-1 predominou durante o meio do dia e início da tarde. Durante a noite até as primeiras horas da manhã, uma componente descendente, menos robusta, com uma velocidade de até 0.5 m.s- 1 foi observada. 0 fluxo horizontal médio $(\mathrm{u}, \mathrm{v})$ foi de baixa velocidade (em torno de $1 \mathrm{~m} . \mathrm{s}-1$ ) e predominantemente de sudeste. Houve uma mudança consistente na direção deste vento, que girou para leste durante a manhã conforme o ramo ascendente se desenvolveu. É proposto um modelo para a circulação do ar próximo à superfície na qual esta mudança na direção do vento é o principal efeito do edifício na turbulência observada. Concluiu-se que outros padrões assimétricos observados, do tipo brisas de vale, podem ser compreendidos como circulações secundárias que tem como pano de fundo o efeito do edifício.
\end{abstract}

\section{Palavras-chave}

Espaços livres. Turbulência atmosférica. Anemômetro sônico.

\section{Daily evolution and seasonal variation of atmospheric turbulence in open spaces in Western Sao Paulo State, Brazil}

\begin{abstract}
This paper seeks to identify a pattern of air turbulence that reflects the effect of buildings on air turbulence characteristics measured in open spaces in Western São Paulo State, Brazil. Atmospheric turbulence was estimated using high-frequency observations of the three orthogonal wind components $(\mathrm{u}, \mathrm{v}, \mathrm{w})$. A CSAT3 sonic anemometer from Campbell Scientific Inc. (CSI) was deployed on the roof of a building, and the turbulent components ( $\left.u^{\prime}, v^{\prime}, w^{\prime}\right)$ were systematically measured and recorded at $0.1 \mathrm{~s}$ and 5 min intervals, respectively, over 1 year between March 2015 and February 2016 with a CR3000 automatic data acquisition system (CSI). The data analysis took into account the diurnal and nocturnal variability of the turbulence, and the experimental results revealed the existence of a daily vertical circulation pattern. The w component varied between 15 and $45 \mathrm{~cm} . \mathrm{s}-1$ on average, and the turbulent fluctuations observed indicated that an ascending component with a speed of up to $1 \mathrm{~m} . \mathrm{s}-1$ predominated during the middle of the day and early afternoon. Throughout the night until the early hours of the morning, a less robust, subsiding component with a speed of up to $0.5 \mathrm{~m} . \mathrm{s}-1$ was observed. The mean horizontal flow ( $\mathrm{u}, \mathrm{v}$ ) was low-speed (around $1 \mathrm{~m} . \mathrm{s}-1$ ) and predominantly from the southeast. There was a consistent change in the direction of this wind, which changed to easterly during the morning as the ascending branch developed. We propose a model for air circulation close to the surface in which this change in direction of the wind is the main effect of the building on the observed turbulence. The conclusion was that other asymmetric patterns observed, as valley breezes, could be understood as secondary circulations that had as backdrop the effect of the building.
\end{abstract}

\section{Keywords}

Open spaces. Atmospheric turbulence. Sonic anemometer. 


\section{Introdução}

A turbulência não é completamente aleatória; ela é quase aleatória (Stull, 1988). Quando sensores de resposta rápida são instalados em um espaço livre no topo de um edifício, os sinais correspondentes aos turbilhões soprados pelo vento parecem ser aleatórios. No entanto, quando estes sinais são cuidadosamente examinados por um longo período, um sinal estatisticamente robusto pode ser observado. Este estudo procura determinar a componente robusta da turbulência e separa-las das flutuações aleatórias sob a hipótese de que a natureza das flutuações turbulentas em espaços livres pode ser analisada se de antemão conhecermos a componente não aleatória da turbulência, que é influenciada pelo edifício onde os sensores são instalados.

As caraterísticas materiais e morfológicas do ambiente construído e a evolução diurna e noturna da camada limite na superfície definem os padrões turbulentos da atmosfera que podem ser identificados próximos à superfície. Uma compreensão da camada limite na superfície, a camada mais baixa da atmosfera, a qual preenche e cobre o dossel urbano (Garrat, 1992), pode beneficiar a construção de assentamentos urbanos sustentáveis (Oke, 2006). À luz disto, espera-se que os resultados deste estudo confirmem Landsberg (1956), que discutiu as vantagens em considerar fatores microclimatológicos no planejamento urbano.

Estudos elaborados nas últimas décadas têm considerado os fluxos turbulentos convectivos, como um dos efeitos primários observados dos edifícios na atmosfera urbana. A distribuição espacial dos edifícios em áreas urbanas está associada com mudanças morfológicas que afetam as trocas de energia com a atmosfera, especialmente os fluxos convectivos, levando ao surgimento de zonas climáticas intra-urbanas (Stewart \& Oke, 2012). Estas zonas climáticas podem estar associadas a diferentes paisagens urbanas. Tarifa e Armani (2001), ao estudarem paisagens urbanas e zonas climáticas na cidade de São Paulo, utilizaram elementos climáticos secundários tal como temperatura e poluição do ar e os relacionaram aos fatores geográficos em duas escalas diferentes (local e micro), mas complementares. Os fluxos convectivos turbulentos de calor sensível e latente foram quantificados pela primeira vez em estudos de balanço de energia sobre uma superfície natural utilizando-se gradientes de temperatura e pressão de vapor observados por Bowen em 1926. Nas décadas subsequentes as superfícies urbanas evoluíram consideravelmente, e as superfícies naturais foram substituídas pelas cidades que armazenam quantidades crescentes de calor antropogênico, energia natural e modificam a ventilação na superfície e o balanço de energia (Ribeiro \& Azevedo, 2003).

Os maiores esforços têm sido feitos desde 2006 para analisar em detalhes a distribuição especial e temporal dos fluxos radiativos e turbulentos dentro da camada do dossel urbano no Estado de São Paulo, inicialmente em áreas densamente urbanizadas no leste do Estado (Machado \& Azevedo, 2013) e a partir de 2012 no oeste do Estado (Barboza \& Machado, 2015), onde a urbanização ainda está em seus estágios iniciais.

Por estes motivos, decidiu-se pôr em operação um estudo controlado de campo para investigar padrões atmosféricos da turbulência próxima à superfície. É razoável supor que, além de ser influenciada pela frota de veículos e por um grande número de pedestres (Azevedo, 2004), a turbulência é influenciada pela posição dos edifícios em relação ao sol e à exposição destes ao vento. Isto validaria as observações e estimativas dos fluxos turbulentos adquiridos sobre estruturas próximas ao chão e em meio a espaços livres.

\section{Método da Correlação Turbulenta}

Por causa da natureza turbulenta do ar, todas as variáveis atmosféricas apresentam flutuações de curto intervalo de tempo em torno de uma flutuação média mais lenta. Os turbilhões movem-se continuamente ao redor das superfícies, a partir das quais derivam suas propriedades. Consequentemente, pode-se dizer que uma variável (s) consiste de seu valor médio $(\bar{s})$ e de uma componente flutuante (s') (Oke, 1987, p.376) de modo que:

$$
S=\bar{S}+S^{\prime}
$$

(C) Labor \& Engenho, Campinas [SP] Brasil, v.10, n.4, p.330-342, out./dez. 2016. 
onde a barra indica uma propriedade média no tempo e a apóstrofe o desvio instantâneo a partir da media. A Figura 3a mostra muito claramente como flutuações na componente vertical do vento $(w)$ e na temperatura $(T)$, por exemplo, se combinam para produzir o fluxo instantâneo de calor sensível $\left(Q_{H}\right)$. A intensidade do fluxo instantâneo é calculada a partir da media do produto das intensidades das flutuações, uma técnica conhecida como correlação turbulenta.

A evolução diurna e noturna das três componentes do vento $(u, v, w)$ e de suas flutuações $\left(u^{\prime}, v^{\prime}, w^{\prime}\right)$ podem ser analisadas em detalhes com a ajuda de um anemômetro sônico CSAT3 da Campbell Scientific Inc. utilizando-se a relação descrita na Equação 1.

A observação da componente vertical das flutuações turbulentas ( $(w)$ é particularmente útil para estimar os fluxos turbulentos convectivos tanto de calor sensível $\left(Q_{H}\right)$ quanto de calor latente $\left(Q_{E}\right)$, os principais fluxos responsáveis pela dissipação da energia armazenada em um volume construído $\left(\Delta \mathrm{Q}_{\mathrm{s}}\right)$. A variabilidade de $\Delta \mathrm{Q}_{\mathrm{s}}$ é proporcional à diferença entre as fontes e os sumidouros de energia, podendo ser definida em termos de um balanço:

$$
\Delta \mathrm{Q}_{\mathrm{S}}=\left(\mathrm{Q}^{*}+\mathrm{Q}_{\mathrm{F}}\right)-\left(\mathrm{Q}_{\mathrm{H}}+\mathrm{Q}_{\mathrm{E}}+\Delta \mathrm{Q}_{\mathrm{A}}\right)
$$

Onde $Q^{*}$ é a densidade do saldo-radiativo em todos os comprimentos de onda observado diretamente com um saldo-radiômetro NR-LITE-2 da Kipp \& Zonen (KZ), $\Delta Q_{A}$ o calor advectado pela componente horizontal dos ventos $(u, v)$ e $Q_{F}$ representa o calor produzido pela atividade humana. Um inventário de $Q_{F}$ para atividades específicas foi compilado para o Oeste Paulista (Finati \& Machado, 2015); os valores de $Q_{F}$ neste inventário são uma ordem de magnitude menor do que os valores para $Q^{*}$. Devese sublinhar que todos os termos no balanço de energia da superfície são fortemente influenciados pelos diferentes tipos de tempo atmosférico que predominam na área (Pradella, 2014). Por esta razão, para realçar o efeito da superfície na variabilidade temporal da turbulência, o conjunto completo de 1 ano de dados foi comparado a uma amostra de 100 dias de observações tomada no início da estação seca, quando as condições de céu claro tendem a predominar.

\subsection{Breve caracterização das localidades onde as flutuações turbulentas foram monitoradas}

O Oeste Paulista é a mais ocidental de todas as regiões do estado de São Paulo e está localizada na confluência do vale do rio Paranapanema com o vale do rio Paraná. A cidade mais populosa na área estudada é Presidente Prudente $\left(22^{\circ} 07^{\prime} 47^{\prime \prime}\right.$ S, $\left.51^{\circ} 24^{\prime} 31^{\prime \prime} \mathrm{W}\right)$, situada a aproximadamente 600 $\mathrm{km}$ do Oceano Atlântico e localizada a aproximadamente $400 \mathrm{~m}$ acima do nível do mar. Abrange uma área municipal de aproximadamente $562 \mathrm{~km}^{2}$, onde vivem mais de 200 mil habitantes (IBGE, 2012) adensados no interior de uma malha urbana de cerca de $30 \mathrm{~km}^{2}$.

As campanhas foram realizadas em Presidente Prudente e depois nas cidades de Iepê e Assis, a sudeste de Presidente Prudente. A Figura 1 mostra os principais aspectos da superfície do terreno na área urbana de Presidente Prudente (Figura 1a) e de Assis (Figura 1b), nos extremos noroeste e sudeste, respectivamente, da área de estudo (Figura 1c), com destaque à micro bacia do córrego do Veado (Figura 1d) em Presidente Prudente, em cuja vertente sul está localizada a estação meteorológica. A topografia amostrada e georreferenciada durante a campanha de 2012 mostrou que a altitude média em Presidente Prudente é aproximadamente 100 metros menor do que em Assis. A forma do terreno na área urbana de Iepê é significativamente mais simples do que em Presidente Prudente e Assis e por isto não é destacada na Figura 1. Consiste essencialmente de um plano inclinado voltado para oeste próximo ao fundo do vale do Rio Paranapanema em torno de $500 \mathrm{~m}$ acima do nível do mar. A área urbana de Assis está localizada à beira de um terraço intermediário, enquanto Presidente Prudente localiza-se sobre um espigão.

A paisagem das cidades no Oeste do Estado de São Paulo é caracterizada por uma grande variedade de formas urbanas, um aspecto típico da paisagem contemporânea brasileira (Macedo, 2012). Nos anos recentes o contraste entre espaços livres, tal como praças, zonas de pedestres e áreas centrais, e, por outro lado, espaços privativos, tal como conjuntos habitacionais, condomínios fechados e jardins privados, têm aumentado acentuadamente. A forma urbana contrasta contundentemente com a área rural ao redor. 

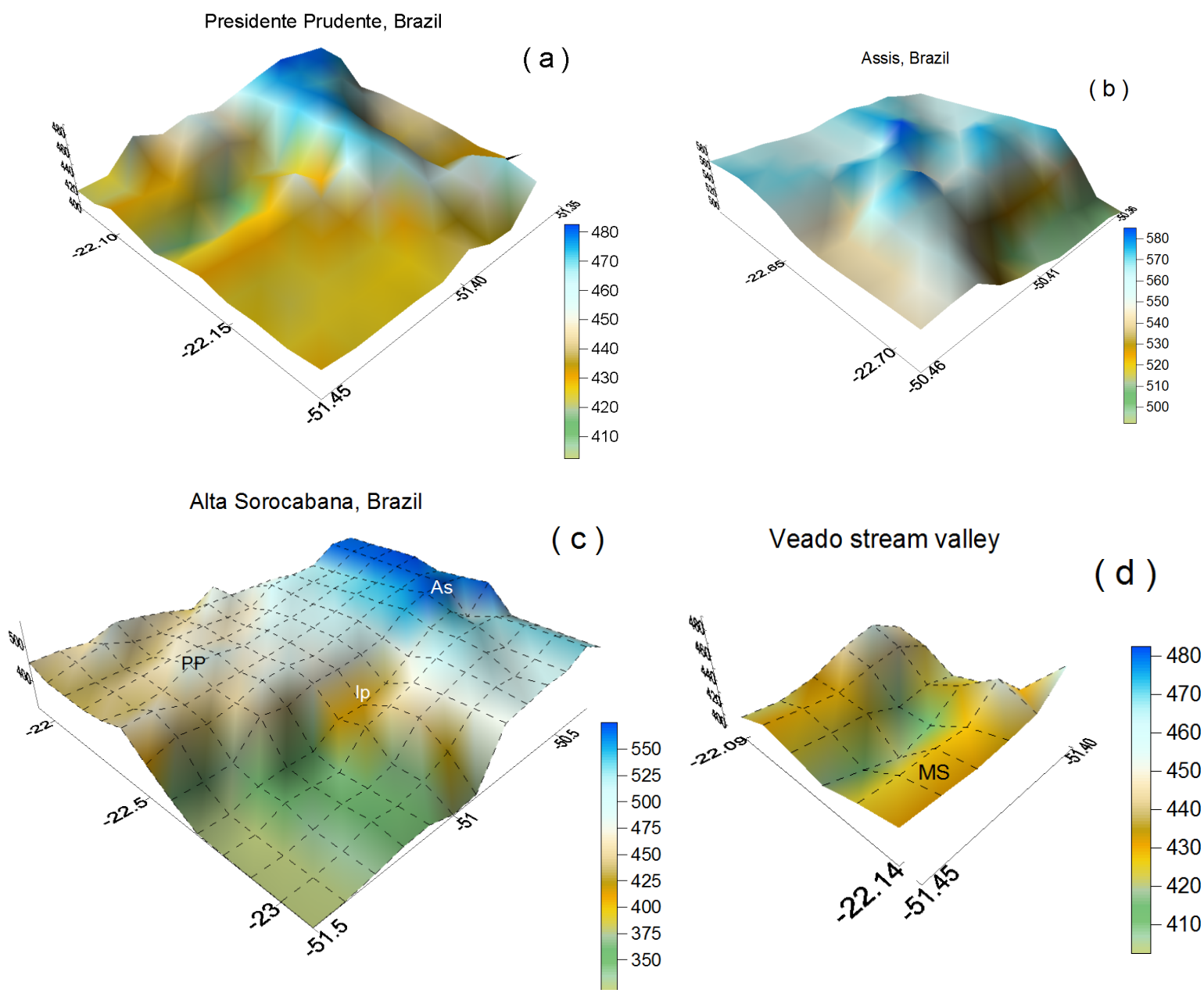

Figura 1. Localização geográfica e topografia amostrada em metros acima do nível do mar para a área urbana de Presidente Prudente (a), Assis (b), a região da Alta Sorocabana no Oeste do Estado de São Paulo incluindo-se Iepê (c) e a micro bacia do córrego do Veado (d) a noroeste da área urbana amostrada em Presidente Prudente, em cuja vertente sul localiza-se a Estação Meteorológica (MS).

\subsection{Experimentos de campo em espaços livres do Oeste Paulista}

Duas campanhas foram realizadas para coletar dados, a primeira em 2012 e a segunda em 2015. Na primeira, os experimentos foram realizados em várias localidades de Presidente Prudente, Assis e Iepê, enquanto em 2015 um único experimento foi realizado em uma determinada localidade de Presidente Prudente. Este estudo trata principalmente sobre a análise dos dados coletados na campanha de 2015. A mesma estratégia foi utilizada tanto na campanha de 2012 quanto na de 2015: instalação de um sensor CSAT3 (CS), saldo-radiômetro (KZ), pirgeômetro (KZ) e termohigrômetro (Vaisälla) em estruturas urbanas existentes a alturas entre 1 e $3 \mathrm{~m}$ acima do chão (Figuras 2a e 2b).

Séries temporais de dados para as componentes do vento, saldo-radiativo, fluxo radiativo em ondas longas, temperatura e umidade do ar foram registradas nestas localidades em intervalos de tempo variando desde algumas horas até um ciclo diurno completo entre o nascer e o pôr do sol. Os dados de vento, que são o objeto de análise neste estudo, foram adquiridos automaticamente com um sistema de aquisição de dados CR3000 (CSI) a uma frequência de $10 \mathrm{~Hz}$ e armazenados em intervalos de $1 \mathrm{~s}$. Todos os locais de observação foram georreferenciados, e suas elevações acima do nível do mar amostradas com um GPS automático (Garmin). 
Em março de 2015 o CSAT3 foi instalado sobre o prédio da Estação Meteorológica de Presidente Prudente (Figuras 2c e 2f) em um experimento controlado e permaneceu em operação até fevereiro de 2016. As componentes do vento foram registradas continuamente durante o dia e a noite. A frequência de amostragem de $10 \mathrm{~Hz}$ utilizada na campanha de 2012 foi mantida, mas o intervalo de registro foi aumentado para $5 \mathrm{~min}$.

Durante a campanha de 2012, foram realizadas medições sobre o mobiliário urbano de praças públicas e avenidas (Figuras 2i e 2j) e ocasionalmente próximo a áreas rurais (Figuras 2d e 2e). Ao contrário de outras cidades, as áreas verdes em espaços livres de Presidente Prudente (Figuras $2 \mathrm{~h}$ e $2 \mathrm{k}$ ) são muito mais utilizadas como lugares de passagem do que como lugares de permanência. Como uma regra geral, existem poucas árvores (Figura 2l). Os projetos destes espaços verdes tendem a se basear em um formalismo geométrico recorrente (Figuras 2g e 2i), e mesmo as formas e revestimentos das fachadas das igrejas variam pouco. Um número muito limitado de edifícios mantém o seu valor cultural e histórico (Figura 2j), ilustrando um patrimônio arquitetônico mal ou inadequadamente restaurado herdado dos europeus que colonizaram a região na primeira metade do século 20.
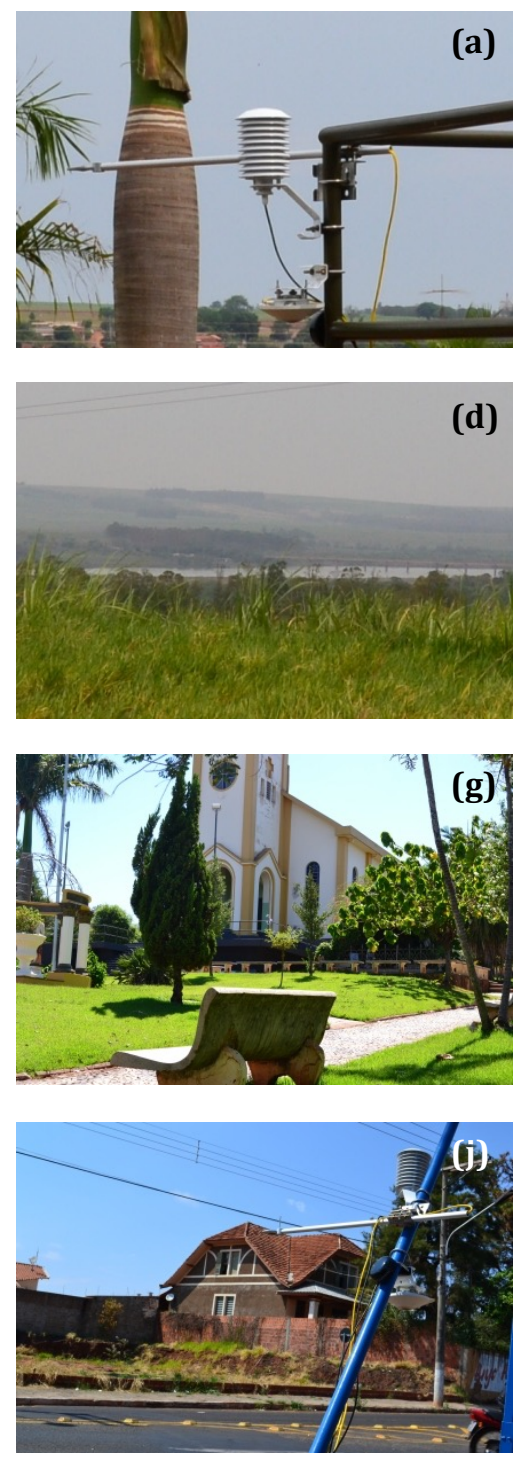

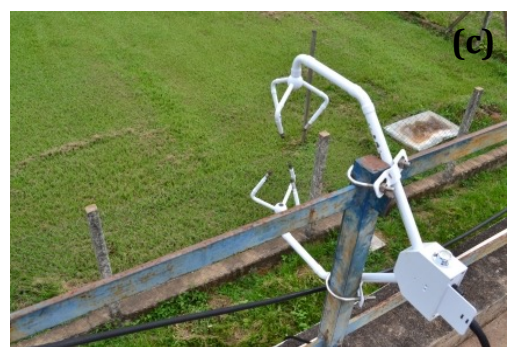

(e)

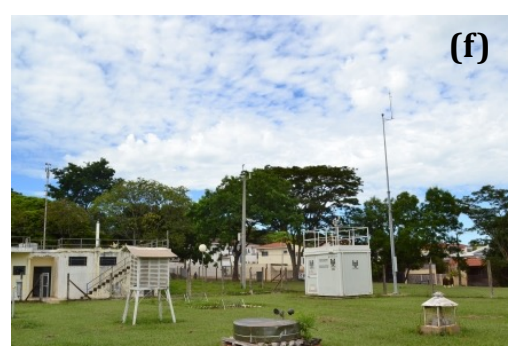

(h)
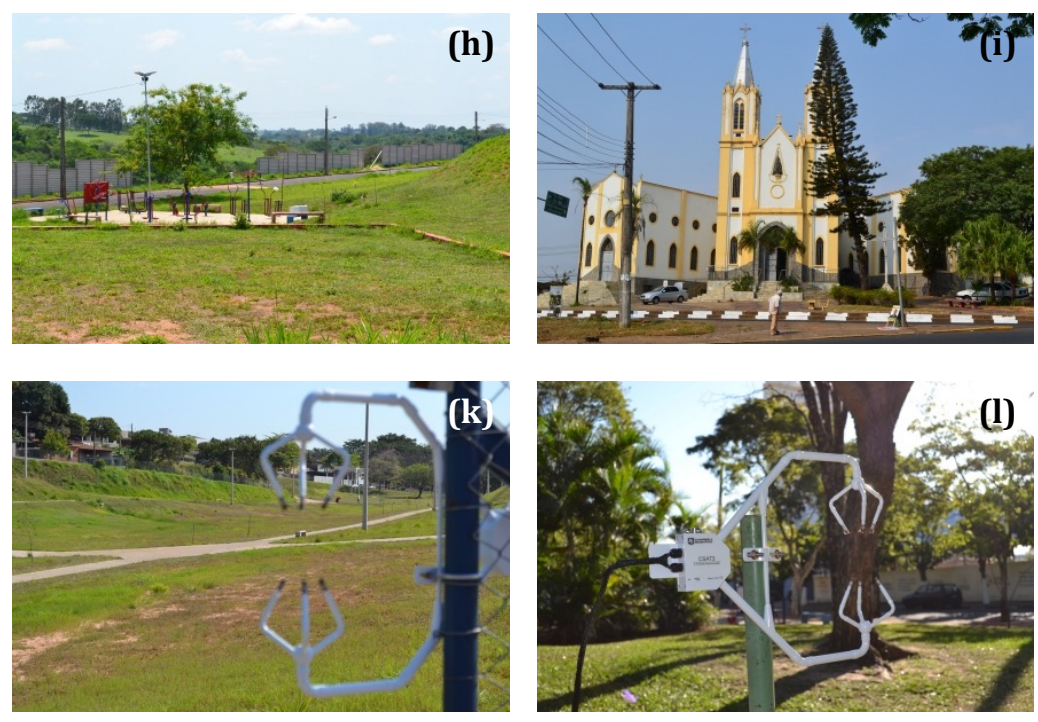

Figura 2. Saldo-radiômetro, pirgeômetro, termo-higrômetro (a) e anemômetro sônico (b, c) instalados na Praça Padre Francisco Penskoffer em Iepê (g), próximos a uma barragem (d), a um campo arado (e) a a estação meteorológica na FCT/UNESP (f). Espaços livres em Presidente Prudente (h, i, k, l) e patrimônio histórico em Assis (j). 


\section{Resultados}

\subsection{Eventos de explosões convectivas observadas utilizando-se a correlação turbulenta}

Um grande turbilhão foi observado em Iepê em meio a pequenos turbilhões (Figura 3). Aparentemente foi um grande turbilhão que teve início no lago da barragem ou no extensor campo arado próximo à cidade. 0 balanço de energia na superfície, que depende da remoção de calor pelo fluxo convectivo $Q_{H}$ (Figura $3 a$ ), sugere uma brisa intra-urbana possivelmente causada por um evento convectivo explosivo (Figura 3b). A brisa é caracterizada por uma mudança súbita na direção do vento entre $13 \mathrm{~h} 45$ e $13 \mathrm{~h} 50$, tornando-se consistentemente de sul, enquanto antes e após o evento ela é predominantemente de norte.

O fluxo de calor sensível dissipado por este grande turbilhão alcança a marca impressionante de $8000 \mathrm{Wm}^{-2}$ durante este período de $5 \mathrm{~min}, 400$ vezes o fluxo $\mathrm{Q}_{\mathrm{F}}$ médio produzido pelas atividades humanas em uma metrópole que se estende ao longo de $2.500 \mathrm{~km}^{2}$ (Azevedo, 2001).

Em uma tentativa de ilustrar a dinâmica destes grandes turbilhões, várias representações esquemáticas da circulação do ar na camada limite associada às características básicas da topografia e da cobertura do terreno são propostas (Figuras 3c-h). Esta relação entre, por um lado, a circulação e, por outro, a morfologia urbana e do terreno pode ser a razão para os padrões diurnos e noturnos da turbulência observada.

As medições realizadas no Oeste Paulista indicam que o vento sopra principalmente de leste. Dependendo da orientação geográfica e localização do assentamento urbano, este fluxo leva a diferentes configurações da turbulência durante o dia e a noite. Cada uma das áreas urbanas estudadas aqui tinham localizações e orientações muito diferentes: a cidade de Iepê está localizada próxima ao fundo do vale do Paranapanema, Assis está mais acima sobre um amplo terraço e Presidente Prudente estende-se ao longo de um espigão sobre as terras baixas que conduzem ao vale do Paraná. A área urbana de Iepê está situada sobre uma encosta voltada para o poente, e a cidade de Assis encontra-se em uma direção leste-oeste margeada ao sul pela borda do terraço que conduz ao rio Parapanema, enquanto Presidente Prudente encontra-se principalmente em uma direção norte-sul no topo das colinas que compõem o espigão que se encontra na mesma direção.

Nas representações esquemáticas baseadas em observações na superfície, os grandes turbilhões circulam em ângulos retos ao vento predominante em Assis, enquanto em Iepê e Presidente Prudente os grandes turbilhões formados nas encostas íngremes opõem-se ou seguem a circulação predominante e são, portanto, favorecidos ou inibidos por ela.

No caso de Assis, a localização do sítio urbano sobre um planalto no topo de uma vertente contribui para desviar os turbilhões acima do dossel urbano. Uma versão mais intensa do mesmo efeito pode ser observada em Presidente Prudente, onde a variação das elevações é $50 \mathrm{~m}$ maior do que em Assis (Figuras 3a e 3b) e existem mais prédios altos, ambos fatores que conduzem a um aprofundamento da camada limite turbulenta.
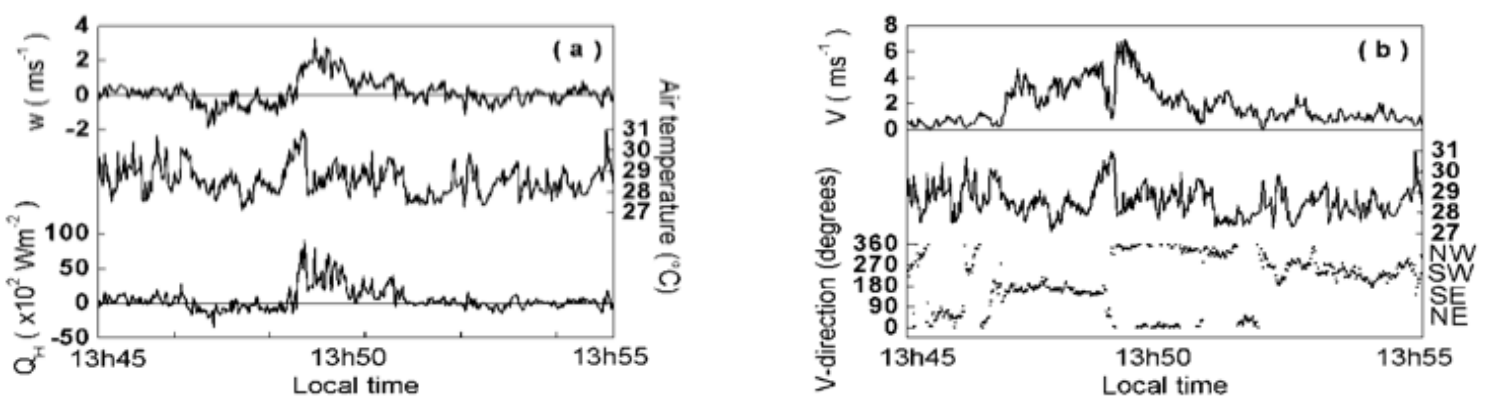

Figura 3a. Comparação de um grande turbilhão entre pequenos turbilhões representados pelo fluxo $Q_{H}(a)$ e a brisa observada (b). 

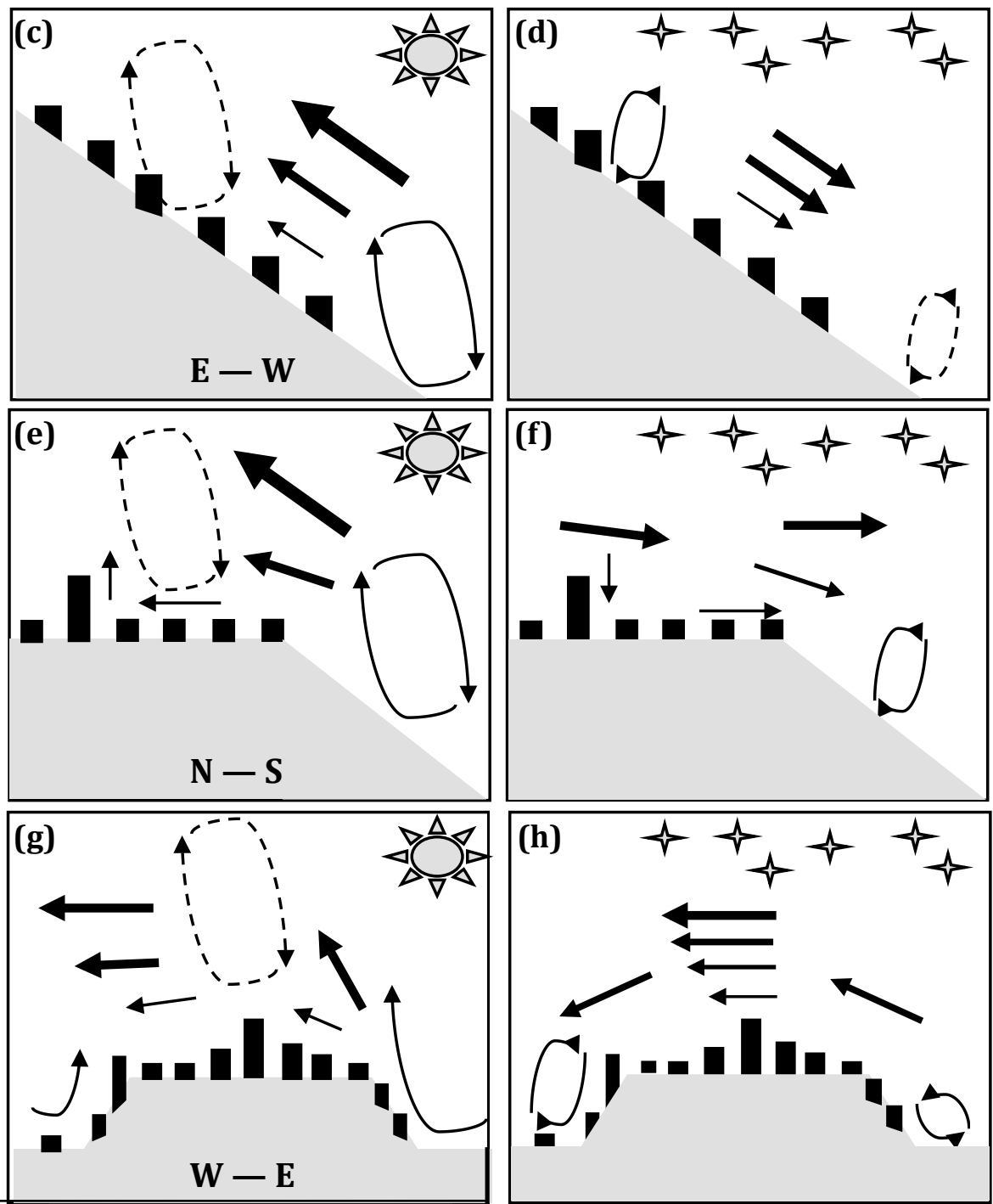

Figura 3b. Comparação de um grande turbilhão entre pequenos turbilhões representados esquematicamente nos instantes $\mathrm{t}$ (linha sólida) e $\mathrm{t}+1$ (linha pontilhada) de grandes turbilhões na circulação da camada limite durante o dia $(c, e, g)$ e à noite $(\mathrm{d}, \mathrm{f}, \mathrm{h})$ em Iepê (c, d), Assis (e, f) e Presidente Prudente (g, h). As áreas em cinza claro representam os perfis topográficos para cada uma das áreas urbanas estudadas, e os retângulos pretos representam os edifícios. A direção da circulação é mostrada para uma direção meridional (N-S) e para uma direção zonal (E-W ou W-E).

\subsection{Evolução diurna e noturna da turbulência dentro da camada do dossel urbano}

A turbulência atmosférica na camada do dossel urbano é altamente complexa. A observação continua da variabilidade da componente vertical do vento $(w)$ e de sua flutuação $(w)$ bem como da variabilidade da componente horizontal do vento $(u, v)$ indicam que existem padrões diurnos e noturnos (Figura 4). As flutuações da componente horizontal $\left(u^{\prime}, v^{\prime}\right)$, que também foram medidas mas não são mostradas aqui, foram desprezíveis comparadas com $w^{\prime}$ e serão discutidas em um próximo estudo. Inicialmente $w$ é analisado em relação à componente horizontal, à direção do vento e à temperatura virtual. Em seguida a variabilidade observada da componente vertical é incluída na análise. A intensidade da turbulência é diretamente proporcional a esta variabilidade, e pode-se notar que a turbulência aumenta conforme a velocidade do vento aumenta. Este efeito mecânico é também acompanhado por um efeito térmico. Conforme o aquecimento diurno intensifica-se durante a manhã, um aumento na intensidade da turbulência também pode ser observado apesar de ventos relativamente fracos com velocidades inferiores a $2 \mathrm{~m} . \mathrm{s}^{-1}$ predominarem.

A Figura 5 mostra a evolução da componente vertical, da componente horizontal, da direção do vento e da temperatura virtual durante o dia e a noite para os meses do ano. Inicialmente a componente horizontal tende a ser mais fraca a partir do início da noite até logo após o amanhecer 
(Figura 5b). Este padrão se fortalece durante o outono e o inverno, quando velocidades do vento superiores a 2 m.s. $\mathrm{s}^{-1}$ são observadas entre as $8 \mathrm{~h}$ e as $12 \mathrm{~h}$. Episódios esporádicos de ventos moderados durante a noite podem estar relacionados a um jato noturno de baixos níveis, um fenômeno meteorológico associado à estratificação noturna da baixa atmosfera que é mais pronunciada em situações de inversão térmica próxima à superfície.

A componente vertical também é mais intensa durante o outono e o inverno (Figura 5a), com uma corrente ascendente quase permanente mais bem definida durante o dia do que à noite. A direção da componente horizontal é mostrada na Figura $5 \mathrm{~d}$. Os ventos de sudeste predominam, com uma tendência a soprar de nordeste durante o dia nos meses de outono e inverno, voltando-se de sudoeste entre o fim da manhã e o início da noite nos meses de primavera e verão.

Para esclarecer se a circulação estava sujeita a efeitos térmicos, a temperatura virtual (TV) estimada pelo CSAT3 é mostrada na Figura $5 \mathrm{c}$. 0 padrão identificado é similar àquele tipicamente associado a um céu claro, isto é, temperaturas máximas durante as tardes de outubro e dos meses subsequentes de verão e resfriamento durante a madrugada e primeiras horas da manhã dos meses de outono e inverno. Este resultado poderia ser esperado, dada a tendência de ocorrência de mais dias de céu claro no Oeste Paulista.
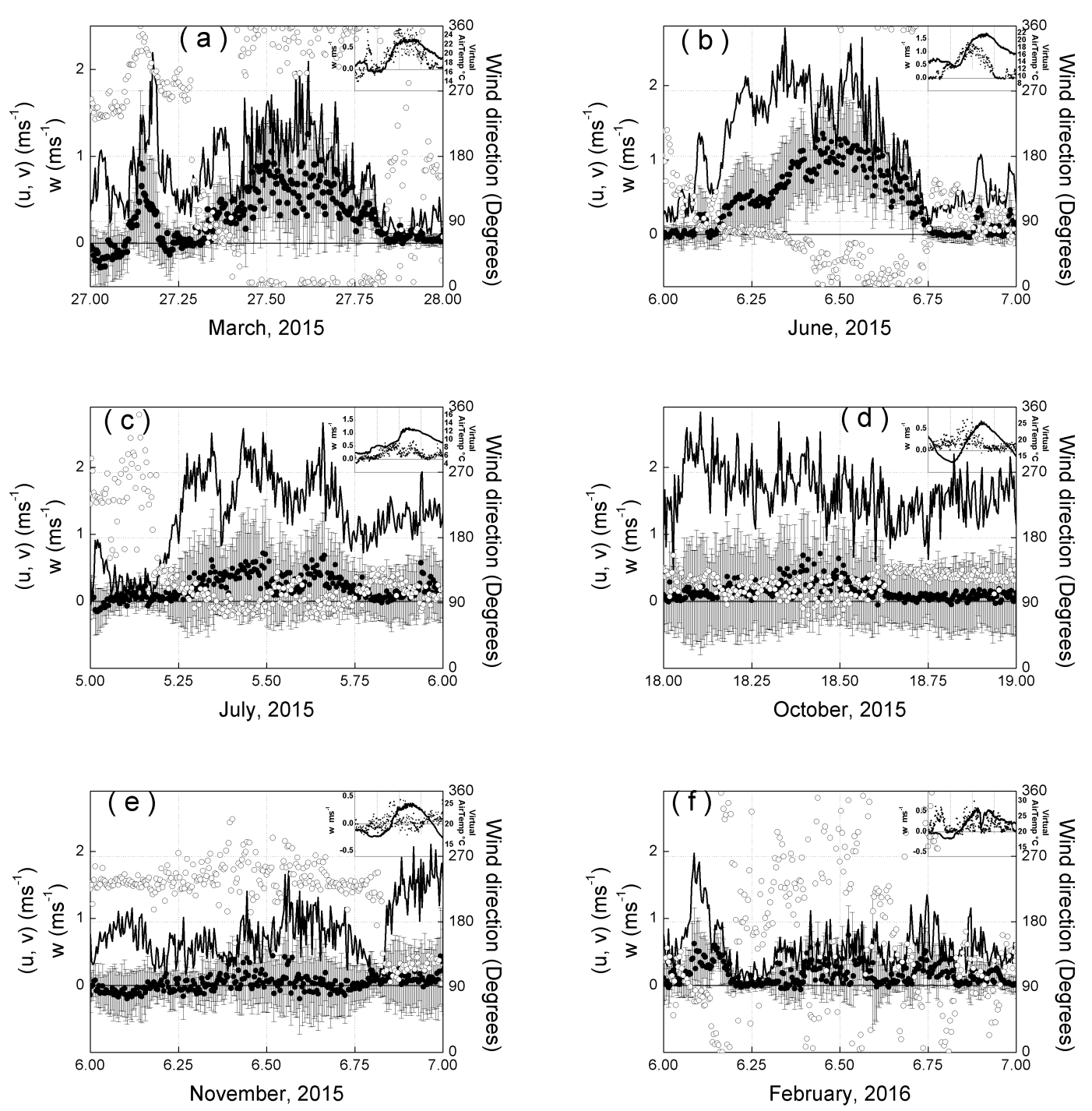

Figura 4. Componente vertical do vento (círculos pretos), componente horizontal do vento (linha contínua) e direção do vento (círculos brancos) em 27 de março (a), 6 de junho (b), 5 de julho (c), 18 de outubro (d), 6 de novembro (e) de 2015 e 6 de fevereiro (f) de 2016. As barras de erro representam o desvio padrão da componente vertical do vento. 0 gráfico no canto superior direito mostra a componente vertical (círculos) e a temperatura virtual (linha contínua). 

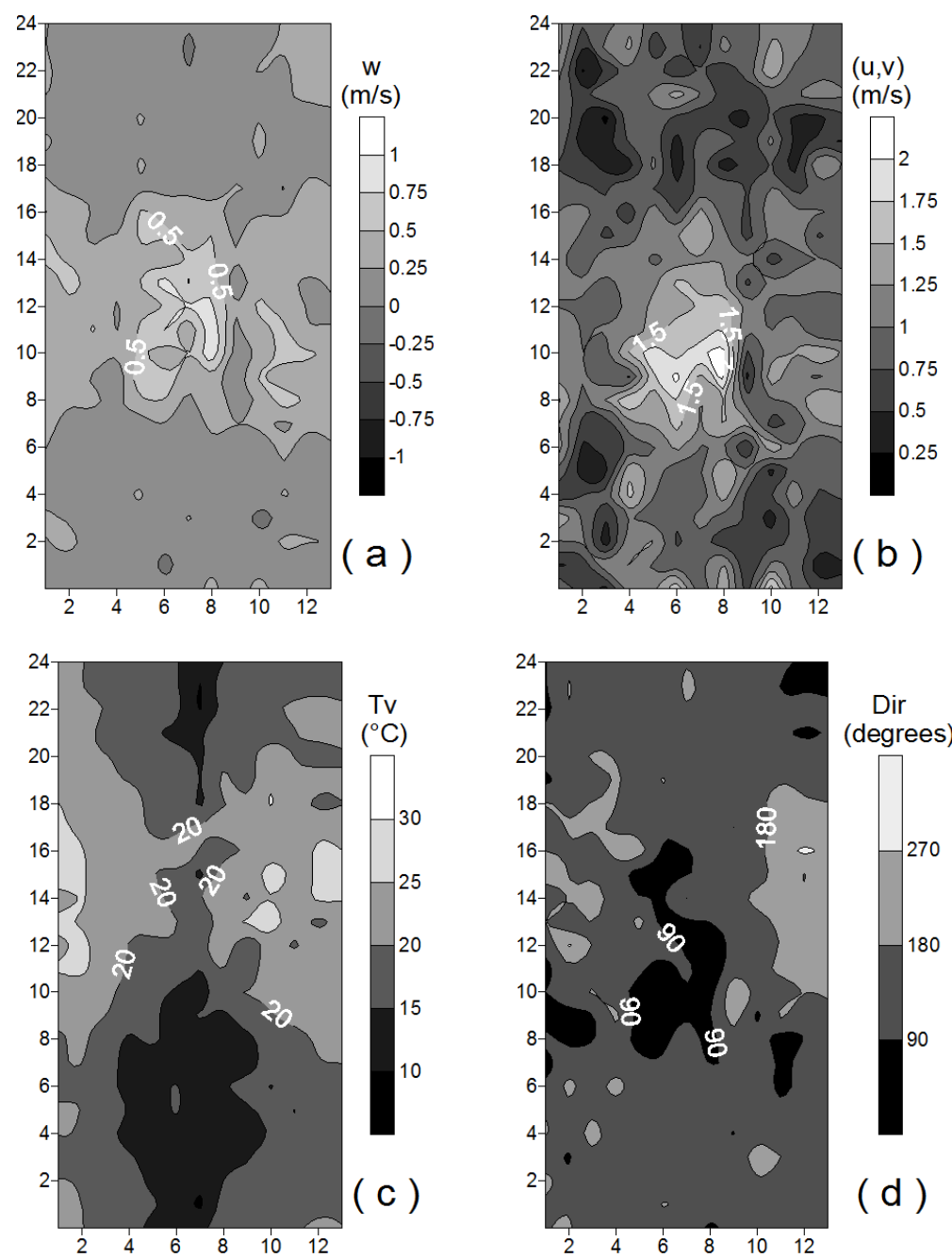

Figura 5. Componente vertical do vento (a), componente horizontal do vento (b), direção do vento (c) e temperatura virtual (d) em função do tempo (eixo vertical) e do mês do ano (eixo horizontal). Anemômetro sônico instalado na estação meteorológica da UNESP / Presidente Prudente a partir de março de 2015.

\subsection{Variabilidade esperada}

Os resultados na Figura 6 foram obtidos com o CSAT3 (Figura 2c) instalado sobre a fachada norte do edifício de um andar de telhado plano na estação meteorológica da UNESP (Figura 2f) e são os valores médios dos dados coletados em um período de um ano (Figuras 6a e 6b) e um período de 100 dias durante os meses de outono (Figuras 6c e 6d), entre os meses de março de 2015 e fevereiro de 2016.

A presença de um edifício na paisagem produz mudanças aerodinâmicas no ambiente ao redor, com aceleração da componente ascendente do vento durante a manhã e desaceleração durante a tarde (Figuras 6a e 6c).

O padrão do fluxo de ar sobre a beirada do edifício, em uma das fachadas que está em um ângulo de incidência direta ao vento, é mostrado nas Figuras $6 \mathrm{~b}$ e $6 \mathrm{~d}$. Após o nascer do sol a velocidade do vento aumenta até quase alcançar $1.5 \mathrm{~m} . \mathrm{s}^{-1} \mathrm{e}$ a direção do vento mudar de sudeste para leste. Durante a tarde a velocidade diminui para aproximadamente $0.5 \mathrm{~m} . \mathrm{s}^{-1} \mathrm{e}$ o vento retorna para sudeste.

A componente vertical do vento alcança um máximo antes de $\mathrm{T}_{\mathrm{V}}$ alcança-lo, sugerindo que a corrente ascendente é dirigida pelo aquecimento radiativo da superfície e implicando uma transferência de energia da superfície para a camada do dossel urbano. $\mathrm{T}_{\mathrm{V}}$ segue um ciclo suave com uma variação diária de temperatura de aproximadamente $7^{\circ} \mathrm{C}$ tanto no outono quanto no período anual e diferença de $2^{\circ} \mathrm{C}$ entre o outono e o período anual, indicando que embora os períodos monitorados não fossem 
especificamente escolhidos, o resultado é similar àquele esperado para uma condição de céu claro. Esta observação não é inesperada pois céu claro ou com poucas nuvens predominam durante todo o ano. Apesar de $w$ ser uma ordem de magnitude menor do que $(u, v)$, suas flutuações temporais são da mesma ordem de magnitude que $(u, v)$ durante o outono, porém menores ao considerarse todo o período anual. Isto indica que não somente calor, mas também momentum é transferido pelo fluxo $w$, especialmente durante o outono quando se inicia a estação seca. Não deve ser por acaso que $(u, v)$ eleva-se para um máximo ao mesmo tempo em que a corrente ascendente da manhã se desenvolve, aumentando a complexidade de qualquer análise da presença do edifício na paisagem.
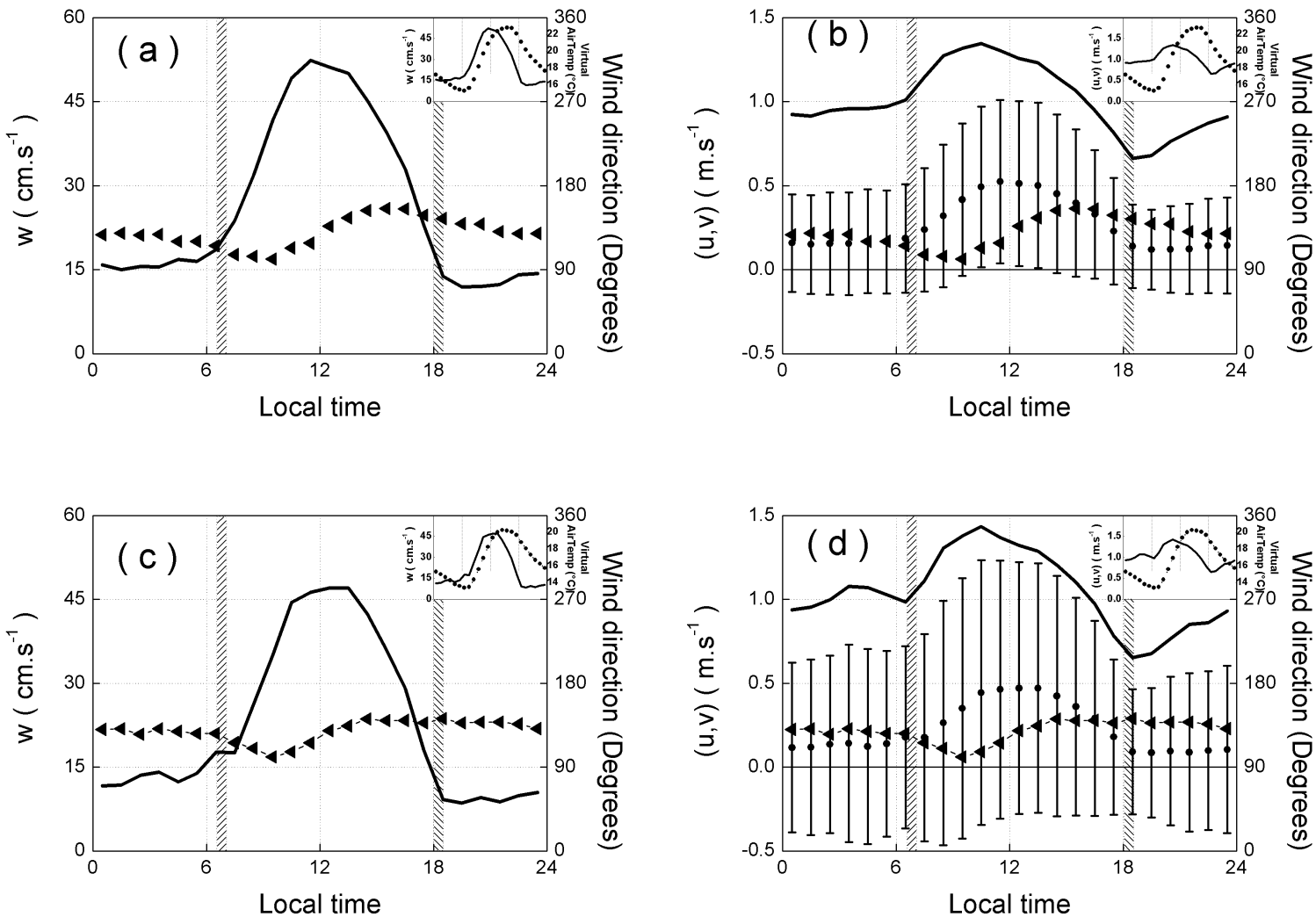

Figura 6. Relação entre a componente vertical $(a, c)$, a componente horizontal $(b, d)$, a temperatura virtual (canto superior direito) e direção do vento (triângulos). Dados coletados com os sensores instalados no topo da fachada norte de um edifício de um andar em frente a uma área coberta por grama para várias condições meteorológicas desde o outono de 2015 até o verão de 2016 (a, b) e apenas para o outono de 2015 (c, d). Os círculos e barras em (b) e (d) representam a flutuação observada na componente vertical (w) mostrada em (a) e (c). As colunas cobertas de hachuras correspondem ao nascer e ao pôr do sol.

\subsection{0 efeito do edifício no fluxo de ar circundante}

Baseado nos resultados apresentados acima, um modelo pode ser elaborado para ilustrar como o fluxo de ar ao redor de um edifício no dossel urbano muda durante o dia (Figura 7). Ao nascer do sol (Figuras 7a e 7c), uma corrente ascendente paralela à fachada norte ganha força. Esta corrente direciona o fluxo sobre o topo do edifício, e o fluxo permanece de leste até o fim da manhã. Após o meio-dia o ar é desviado a partir do topo do edifício conforme o sol se põe no horizonte (Figuras $7 \mathrm{~b}$ e 7d), e esta situação continua durante toda a noite até o amanhecer do dia seguinte. Sem o apoio da corrente subindo, o ar começa a descer pelas paredes do edifício.

Este efeito externo tem implicações no espaço interno. Durante a manhã o ar dentro do edifício adquire as características do ar externo próximo ao chão (que é mais quente e constituído de partículas das superfícies ao redor), circula dentro do edifício e então sai através das janelas mais altas. A partir do meio-dia, e durante toda a tarde e noite até o amanhecer do dia seguinte, o ar dentro do edifício adquire as características do ar mais fresco, mais elevado, que consiste de 
várias partículas transportadas e dispersas a partir das fontes que compõem a estrutura urbana a barlavento do edifício que está sendo analisado.

A reconstituição dos efeitos de escala superior torna-se assim uma tarefa exequível, por exemplo, o caso de uma brisa de vale identificada no dia 6 de junho de 2015 (Figuras 7e, 7f e Figura 4b). A partir deste trabalho é possível determinar o efeito esperado do edifício (Figuras 7c e 7d) e reconhecer outras circulações de ar que evoluem através do sistema de espaços livres. A caracterização da brisa é definida pela direção do vento, que ao invés de manter-se no quadrante sudeste conforme esperado, girou para os quadrantes nordeste durante a manhã (Figura 7e) e noroeste durante a tarde (Figura 7f), retornando de sudeste conforme o sol declinava no horizonte. 0 lastro empírico que parece confirmar a hipótese de uma brisa soprando de norte, a partir do vale do córrego do Veado, é a própria topografia amostrada e georreferenciada ao redor da estação meteorológica (Figura 2d).
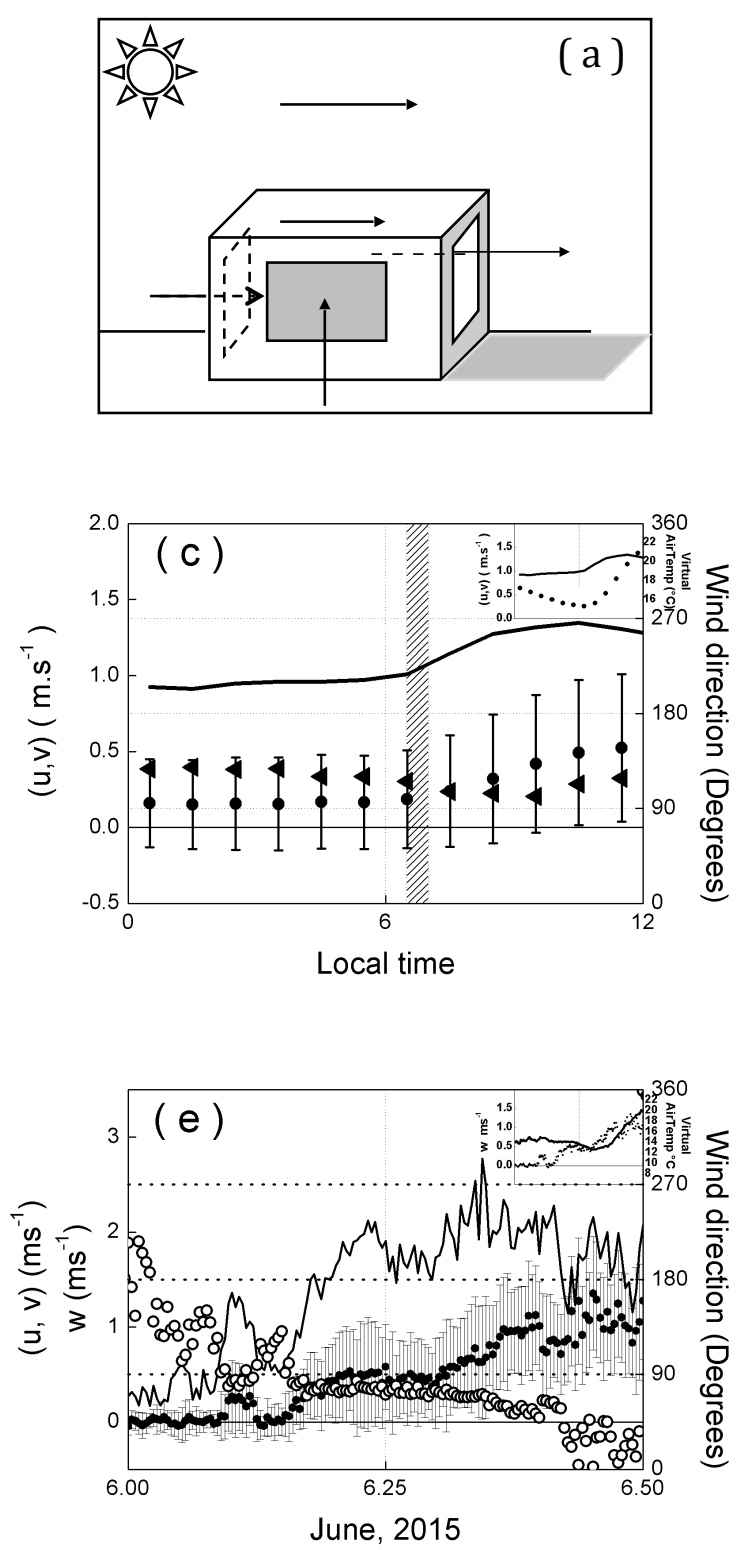
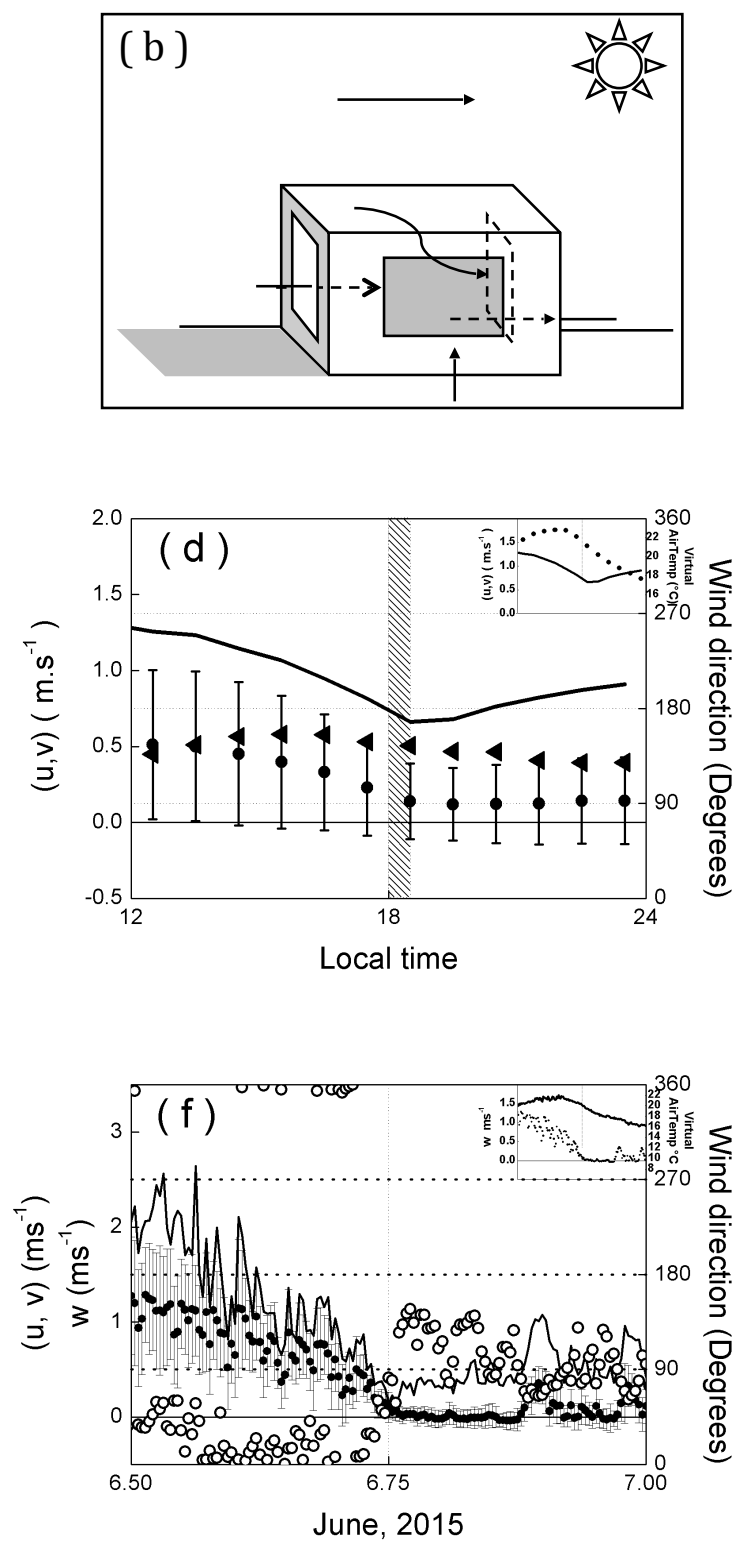

Figura 7. Representação esquemática (baseada nos resultados deste estudo) do fluxo de ar ao redor e através de um edifício cujo eixo principal orienta-se na direção E-W $(a, b)$, padrão anual médio esperado da turbulência atmosférica diária (c, d) conforme a Figura 6 e a turbulência atmosférica observada no dia 6 de junho de 2015 (e, f) conforme a Figura 4, durante a manhã (a, c, e) e à tarde (b,d,f). 


\section{Considerações finais}

Espera-se que os resultados deste estudo ajudem a identificar padrões coerentes na turbulência atmosférica observada próximo à superfície. Ao relacionar uma escala temporal efêmera de apenas alguns poucos minutos a escalas temporais da ordem de horas ou mesmo meses, turbilhões de várias dimensões espaciais podem ser identificados.

A análise da variação sazonal na turbulência seria uma prática sensata, na medida em que permite um padrão diário consistente ser identificado. Este padrão provou-se ser o produto de dois fatores: a convecção térmica espontânea produzida pelo aquecimento e resfriamento da superfície durante o dia e a noite; e a presença do edifício, que em geral intensificou a turbulência mecânica.

Os resultados deste estudo não apenas ajudam a compreender como os fluxos de ar ao redor de um edifício desenvolvem-se durante o dia e a noite, mas também permite avaliar os turbilhões investigados nos espaços livres com um maior grau de certeza. Também se mostram úteis para o desenho de projetos paisagísticos termicamente eficientes. 0 conjunto anual de dados parece validar satisfatoriamente os resultados alcançados com o conjunto restrito aos meses de outono.

Durante o ano estudado foram observados dias com um padrão assimétrico em relação ao padrão esperado. Há evidências da interferência do prédio onde os sensores estão instalados em relação aos fluxos de ar observados. Por outro lado, há evidências da ocorrência de brisas associadas às variações topográficas do terreno sobre o qual se estrutura a malha urbana. Possivelmente a dinâmica do mecanismo de brisa corresponda a uma circulação secundária manifesta sobre um pano de fundo que tem o edifício como fator determinante da circulação primária.

\subsection{Agradecimentos}

O autor agradece à Fundação de Amparo à Pesquisa do Estado de São Paulo (FAPESP) por fornecer suporte financeiro (proc. no. 2011/08520-8) e aos revisores anônimos cujos comentários ajudaram a melhorar este artigo.

\section{Referências}

Azevedo, T. R. de (2001). 0 fluxo de calor gerado pelas atividades humanas. In J. R. Tarifa, \& T. R. Azevedo (Orgs.). Os climas da cidade de São Paulo: teoria e prática. São Paulo: Universidade de São Paulo, FFLCH, Departamento de Geografia.

Azevedo, T. R. de. (2004). A frota de automóveis e o pó que São Paulo respira (particulado inalável no clima da cidade). In A. F. A. Carlos, \& A. U. Oliveira (Orgs.). Geografias de São Paulo: representação e crise da metrópole (Vol. 1, pp. 73-88). São Paulo: Editora Contexto.

Barboza, E. C., \& Machado, A. J. (2015). Bowen ratio in Western São Paulo State, Brazil. Proceedings of the International Conference on Building, Architecture and Urbanism, Barcelona, España, 17. Barcelona: WASET, 2015, v. 17, n. 10, Part XII, p. 1770-1773.

Ferreira, M. J., Oliveira, A. P. de, \& Soares, J. (2013). Diurnal variation in stored energy flux in São Paulo city, Brazil. UC Urban Climate, 5 (1), 36-51 [Amsterdan]. ISSN 2212-0955. Recuperado em 25 setembro 2015, de http://www.sciencedirect.com/science/article/pii/S2212095513000254>. DOI: http://dx.doi.org/10.1016/ j.uclim.2013.06.001

Finati, G. I., \& Machado, A. J. (2015). Evolução diurna do calor antropogênico liberado por cozinhas e sua relação com o balanço de energia à superfície no Oeste Paulista, SP. PARC Pesquisa em Arquitetura e Construção, 6 (2), 103-119 [Campinas, SP]. <http://periodicos.sbu.unicamp.br/ojs/index.php/parc/article/view/8635016>.

Garrat, J. R. (1992). The atmospheric boundary layer. Cambridge University Press.

Instituto Brasileiro de Geografia e Estatística [IBGE]. Disponível em http://www.censo2014.ibge.gov.br/ Acessado em 3 de julho de 2015. 
Landsberg, H. E. (2006). O clima das cidades [Trad. Tarik Rezende de Azevedo]. Revista do Departamento de Geografia, 18, 95-111.

Macedo, S. S. (2012). Paisagismo brasileiro na virada do século: 1990-2010. São Paulo: Edusp; Campinas: Editora da Unicamp.

Machado, A. J., \& Azevedo, T. R. de. (2013). Spatial distribution in long-wave radiation flux in São Paulo city, Brazil. WJEPS World Journal of Engineering and Physical Sciences, 1 (3), 33-52 [Albany]. [ISSN 2331-1878]. Recuperado em 25 setembro, 2015, de http://wsrjournals.org/journal/wjeps

Oke, T. R. (1987). Boundary Layer Climates (2nd ed.). London: Routledge.

Oke, T. R. (2006). Towards better scientific communication in urban climate. Theoretical and Applied Climatology, 84,179-190. DOI 10.1007/s00704-005-0153-0.

Pradella, H. L. (2014). A construção do conceito de "tipos de tempo" entre os séculos XVII e XXI, no âmbito das Ciências Atmosféricas. Dissertação (Mestrado em Geografia Física) — Faculdade de Filosofia, Letras e Ciências Humanas, Universidade de São Paulo, São Paulo, SP, Brasil.

Ribeiro, H., \& Azevedo, T. R. (2003). 0 patrimônio em áreas verdes da USP e atmosfera urbana. In: Comissão de Patrimônio Cultural da USP. Meio Ambiente: Patrimônio Cultural da USP (pp.19-39). São Paulo: Universidade de São Paulo.

Stewart, I. D., \& Oke, T. R. (2012). Local climate zones for urban temperature studies. BAMS Bulletin of American Meteorological Society, 93 (12), 1879-1900 [ISSN 1520-0477]. Recuperado em 25 setembro, 2015, de http:// journals.ametsoc.org/doi/abs/10.1175/BAMS-D-11-00019.1

DOI: http://dx.doi.org/10.1175/BAMS-D-11-00019.1

Stull, R. B. (1988). An Introduction to Boundary Layer Meteorology. London: Kluwer Academic Publishers.

Tarifa, J. R., \& Armani, G. (2001). Os Climas Urbanos. In J. R. Tarifa, \& T. R. Azevedo (Orgs.). Os climas da cidade de São Paulo: teoria e prática. São Paulo: Universidade de São Paulo, FFLCH, Departamento de Geografia. 